\title{
ON THE ULTRASTRUCTURE OF THE CENTRAL DARK LINE OBSERVED BY TEM IN HUMAN TOOTH ENAMEL GRAINS.
}

\author{
Rodríguez Hernández Ana Guadalupe * and Reyes-Gasga José **. \\ * Facultad de Odontología, División de Estudios de Posgrado UNAM. Circuito exterior s/n. 04510 \\ Ciudad Universitaria, D.F. \\ ** Instituto de Física, UNAM. Circuito exterior s/n 04510 Ciudad Universitaria, D.F.
}

The dental enamel is the most highly mineralized tissue in the human body, containing $96 \%$ inorganic material and 4\% organic material and water. The inorganic phase consist of a calcium phosphate known as hydroxyapatite $\left(\mathrm{Ca}_{10}\left(\mathrm{PO}_{4}\right)_{6}(\mathrm{OH})_{2}\right)$. The enamel is formed by a structure socalled enamel prism, which was described as hexagonal and prism-like arrangement. The enamel prism is somewhat like a cylinder and it is as long as the total thickness of the enamel. Its long axes run parallel to the longitudinal axis of the prism.

At the same time the prisms are formed by nano-crystals that have an unknown atomic crystalline defect in their center, and it has been called "central dark line". This defect was first reported by Nylen, Frazier and Ronnholm in studies on both human and rat tooth enamel ${ }^{(1)}$. Ronnholm suggested the possibility that this defect presented different composition than the rest of enamel, and proposed that the central dark line was in a different crystalline stage. Alternatively, he proposed that the central dark line might be a remnant of a calcified organic matrix ${ }^{(1)}$.

The central line appears dark in defocus, disappears as the image is in focus, and regains contrast in over-focus because it is white ${ }^{(2)}$. It has been always presented in healthy enamel as much as in kids or in adults (Fig 1).

Another very important point in this structure is acid dissolution. When a tooth is in an acidic environment, the enamel grains are dissolved in the center as the first place as undergo the attack in the enamel crystals ${ }^{(2)}$. This $\mathrm{pH}$ difference could be either for a presence of bacteria (streptococcus or lactobacillus) or acid etching (37\% phosphoric acid) used by the dentist in a aesthetic restorative procedure.

Kakei Mitsuo ${ }^{(3)}$, talked about the central dark structure in the dental calculus and Nakahara Hirosi $^{(4)}$ in his study showed that the mature dentin crystals and bone, the central dark line first appeared in the middle of a relative electron-lucent area. And he suggest that the central dark line represents the initiation site of crystal growth.

In this work we are going to present recent results on the ultra-structure and chemical composition of the human tooth enamel and the central dark line themselves when they are analyzed with modern microscopes such as the one with a FEG gun that allows to get information from nanoareas, such as the scale of this central defect.

\section{REFERENCES.}


(1) Marshall A.F. and Lawless. TEM Study of the Central Dark Line in Enamel Crystallites. J. Dental Research 60 (10) 1773-1782, Oct. 1981.

(2) Reyes Gasga José, et al. La Microscopia Electrónica y el esmalte dental humano. Ciencia y Desarrollo 125. Nov. Dec. 1995.

(3) Mitsuo Kakei, et al. Demostration of the central dark line In crystals of dental calculus. Biochimica et Biophysica Acta 1524 (2000) 189-195

(4) Hiroshi Nakahara and Kakei Mitsuo. TEM Observations on the crystallites of dentin and bone. Bull Josai Dent. Univ. 13 (2) 1984.

(5) We thanks the technical help from P. Méxia, R. Hernández, M. Aguilar, C. Flores, J. Cañetas, I. Puente Lee, C. Magaña, S. Tehuacanero, C. Zorrilla, L. Rendón, and A. Sánchez. This work was supported by DGAPA-UNAM with the project IN-104902.

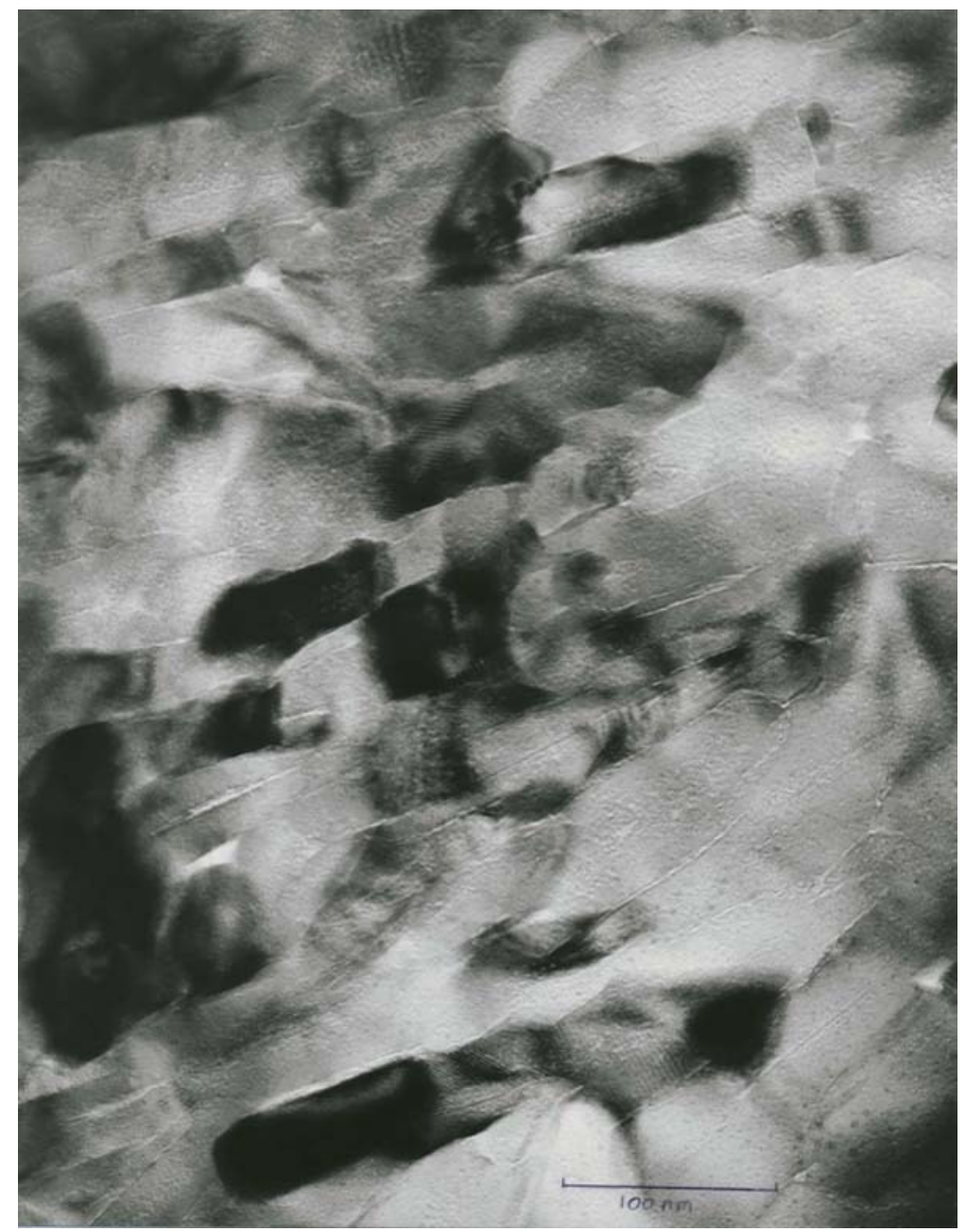

Fig 1. Transmission Electron Micrograph of an enamel section showing some defects in the structure and the central dark line in the center to the crystals. 